\title{
On how religions could accidentally incite lies and violence: folktales as a cultural transmitter
}

\author{
Quan-Hoang Vuong ${ }^{1,2 凶}$, Manh-Tung Ho (1) ${ }^{1,3,4 凶}$, Hong-Kong T. Nguyen ${ }^{1,3}$, Thu-Trang Vuong ${ }^{5}$, Trung Tran (1) ${ }^{6}$, \\ Khanh-Linh Hoang ${ }^{7}$, Thi-Hanh $\mathrm{Vu}^{8}$, Phuong-Hanh Hoang ${ }^{9}$, Minh-Hoang Nguyen ${ }^{3}$, Manh-Toan Ho (i) ${ }^{1}$ \& \\ Viet-Phuong La'
}

\begin{abstract}
Folklore has a critical role as a cultural transmitter, all the while being a socially accepted medium for the expressions of culturally contradicting wishes and conducts. In this study of Vietnamese folktales, through the use of Bayesian multilevel modeling and the Markov chain Monte Carlo technique, we offer empirical evidence for how the interplay between religious teachings (Confucianism, Buddhism, and Taoism) and deviant behaviors (lying and violence) could affect a folktale's outcome. The findings indicate that characters who lie and/or commit violent acts tend to have bad endings, as intuition would dictate, but when they are associated with any of the above Three Teachings, the final endings may vary. Positive outcomes are seen in cases where characters associated with Confucianism lie and characters associated with Buddhism act violently. The results supplement the worldwide literature on discrepancies between folklore and real-life conduct, as well as on the contradictory human behaviors vis-à-vis religious teachings. Overall, the study highlights the complexity of human decision-making, especially beyond the folklore realm.
\end{abstract}

\footnotetext{
${ }^{1}$ Centre for Interdisciplinary Social Research, Phenikaa University, Ha Dong, Hanoi 100803, Vietnam. ${ }^{2}$ Centre Emile Bernheim, Université Libre de Bruxelles, 1050 Bruxelles, Belgium. ${ }^{3}$ Ritsumeikan Asia Pacific University, Oita Prefecture, Beppu City, Jumonjibaru 1-1, 874-8577, Japan. ${ }^{4}$ Institute of Philosophy, Vietnam Academy of Social Sciences, Hanoi, 59, Lang Ha 100000, Vietnam. ${ }^{5}$ Ecole doctorale, Sciences Po Paris, 75337 Paris, France. ${ }^{6}$ Vietnam Academy for Ethnic Minorities, Hanoi 100000, Vietnam. ${ }^{7}$ Institute of Theoretical and Applied Research (ITAR), Duy Tan University, Hanoi 100000, Vietnam. ${ }^{8}$ School of Economics and International Business, Foreign Trade University, Hanoi 100000, Vietnam. ${ }^{9}$ Vietnam National Institute of Educational Sciences, 101 Tran Hung Dao street, Hoan Kiem district, Hanoi 100000, Vietnam. In Memory of the Late Professor Jacques Nagels (1937-2014). ${ }^{-e m a i l: ~ q v u o n g @ u l b . a c . b e ; ~ t u n g . ~}$ homanh@phenikaa-uni.edu.vn
} 


\section{Introduction}

"Le vice se cache souvent sous le manteau de la vertu." French proverb

$$
\text { - }
$$
olklore materials offer one of the most imaginative windows into the livelihood and psychology of people from different walks of life at a certain time. These colorful narratives bring to life the identities, practices, values, and norms of a culture from a bygone era that may provide insights on speech play and tongue-twisters (Nikolić and Bakarić, 2016), habitat quality of farmers (Møller et al., 2017), and contemporary attitudes and beliefs (Michalopoulos and Xue, 2019; Thenmozhi et al., 2018). While the stories tend to honor the value of hard work, honesty, benevolence, and many other desirable virtues, many of such messages are undercut by actions that seem outlandish, morally questionable, or brutally violent (Meehan, 1994; Victor, 1990; Haar, 2005; Chima and Helen, 2015; Alcantud-Diaz, 2010, 2014). For example, in a popular Vietnamese folktale known as "Story of a bird named bim bip (coucal)," a robber who repents on his killing and cuts open his chest to offer his heart to the Buddha gets a better ending than a Buddhist monk who has been religiously chaste for his whole life but fails to honor his promise to the robber-i.e., bringing the robber's heart to the Buddha. In his quest for the robber's missing heart, not only does the monk never reach enlightenment, but he also turns into a coucal, a bird in the cuckoo family. On the one hand, the gory details of this story likely serve to highlight the literal determination and commitment of the robber to repentance, which is in line with the Buddhist teaching of turning around regardless of whichever wrong directions one has taken. On the other hand, it is puzzling how oral storytelling and later handwriting traditions have kept alive the graphic details - the images of the robber killing himself in the name of Buddhism, a religion largely known for its nonviolence and compassion.

Aiming to make sense of these apparent contradictions, this study uses Bayesian hierarchical analysis to analyze the behavior of Vietnamese folk characters as influenced by long-standing cultural and religious factors. Given that there is a certain degree of interactions among the elements constitutive of the three religions of Confucianism, Buddhism, and Taoism-the cultural additivity phenomenon (Vuong et al., 2018), it is reasonable to hypothesize that there may be some relationship between these religiously-imbued teachings and the universally-frowned upon acts of lying and violence. The focus on the folkloristic realm facilitates the discovery of behavioral patterns that may otherwise escape our usual intuitions. Indeed, while scholars have pointed out the prevalence of elements related to violence and lies in folktales (Meehan, 1994; Victor, 1990; Haar, 2005; Chima and Helen, 2015; Alcantud-Diaz, 2010, 2014), few have offered a rigorous statistical method to understand the interactions between these elements and their religio-cultural contexts. Thus, the present study's research method adds to the wave of studies on computational folkloristics, which currently emphasize the digitization of resources, the classification of folklore, and the necessary algorithms for data structure development rather than the statistical analysis of behavioral patterns in folktales (Abello et al., 2012; Tangherlini, 2013; Nguyen et al., 2013; Dogra, 2018; Tehrani and d'Huy, 2017). Moreover, the scope of the present research differs from the largely Euro-centric research projects (Nguyen et al., 2013; Bortolini et al., 2017a, b; d'Huy et al., 2017; Nikolić and Bakarić, 2016), as it contributes to the wave of scholarship on non-WEIRD (Western, Educated, Industrialized, Rich, and Democratic) societies by shedding light on the littleknown behavioral variability and contradictions in the folklore of a developing Asian country (Henrich et al., 2010). The research, thus, aims to resolve the following research question (RQ):
What are the credible statistical patterns for the interaction between negative behaviors (lie and violence) and the values of three major Eastern religious teachings (Buddhism, Taoism and Confucianism) to determine the outcome of folktales? In other words, what kind of outcome could we expect from the interaction of the negative behaviors with the three religious teachings?

\section{Literature review}

In order to situate the study within the literature, it is necessary to see (i) how religious teachings and religions in general are linked to deviant acts such as lying and violence, (ii) how folklore around the world has portrayed lies and violence, and (iii) what the Three Teachings in Vietnam cover.

The relationship between religions and lying or violence. Research on the relationship between religions and lying or violence highlights two notable trends, namely the debatable role of religions in restraining negative behaviors and the skewed attention toward the three great Western religions-Judaism, Christianity, and Islam-and their influence on followers' behavior. First, it is clear that the acts of lying and violence represent deviances to the acceptable moral norms regardless of the cultural and religious settings. When examined through the binary religion-secular dimension, it is widely believed that religiosity, with its emphasis on being, loving, compassionate, honest, humble, and forgiving, should create changes reflecting such virtues in the behavior of the religious followers. This assumption is supported by the theory of cognitive dissonance: because religious people have an internal motivation to behave consistently with their beliefs, any behaviors that are not so would result in dissonance (Perrin, 2000; Festinger, 1962). Along this line of argument, research on the role of religion frequently draws on the work of Emile Durkheim, who recognizes religion as the prime source of social cohesion and moral enforcement (Durkheim, 1897).

Yet, not just the clergymen who have doubts about the constraining effects of religious faith but also scholars over the ages. To make sense of the relationship between religiosity and deviant behaviors, scholars from as far back as the 1960s have sought to measure how church membership or religious commitment could deter delinquent activities, though pieces of empirical evidence over the years remain inconclusive (Albrecht et al., 1977; Rohrbaugh and Jessor, 1975; Tittle and Welch, 1983; Hirschi and Stark, 1969). In their influential study, Hirschi and Stark (1969) ask if the Christian punishment of hellfire for sinners can deter delinquent acts among the firm believers, and surprisingly find no connection between religiosity and juvenile delinquency. Subsequent studies tend to fall along two lines, either confirming the irrelevance of religion and deviance (Tittle and Welch, 1983; Welch et al., 2006; Cochran and Akers, 1989), or pointing out certain inhibiting effect of religiosity depending on the types of religious contexts (Evans et al., 1995; Corcoran et al., 2012; Benda, 2002; Rohrbaugh and Jessor, 2017). Additional studies have looked at religious contexts beyond the WEIRD (Western, educated, industrialized, rich, democratic) countries such as in South Korea and China but also reached inconsistent results on the religiosity-deviance relationship (Wang and Jang, 2018; Yun and Lee, 2016).

Second, in the scholarship on the relationship between religious teachings/commitment and misconduct, the spotlight has largely been on Western monotheistic religions and its punitive supernatural systems. Although non-religious people's moral attitude and behaviors can be drawn from their experiences 
and interactions with religious others (Sumerau and Cragun, 2016), the formulation of moral identity is a complex process involving conceptualization of the self over different developmental stages (Wainryb and Pasupathi, 2015). As such, one needs not define religion merely as a "belief in spiritual beings" but should include the in-between spaces of spirit and non-spirit (E. B. Tylor as cited in Day et al. (2016)). This definition gives room for studying the influence of semi-religious teachings or folk religion in countries where the word religion itself does not evoke the same sentiment or understanding. In this study, Confucianism, Buddhism, and Taoism can either be regarded as religions or loosely as religious teachings for they do not posit an almighty supernatural being but instead focus more on the cultivation of certain sets of virtues. The details of the Three Teachings are explained below.

The portrayal of lies and violence in folklore. The acts of hurting or killing one another are common images in folklore and religious narratives around the world (Meehan, 1994; Victor, 1990; Haar, 2005; Chima and Helen, 2015; Houben and van Kooij, 1999). This is attributable to the role violence plays in human storytelling-as a story device, it gives voices to both the offenders and the victims (Sandberg et al., 2015), as well as serves interactional and recreational purposes (Coupland and Jaworski, 2003). How people tell their stories, lying or being honest, not only reflects but also allows us to grasp the intertwining nature of values, identities, and cultures (Sandberg, 2014). For example, Victor (1990) shows that rumors about the satanic cult-which is rooted in the mythologized ancient blood ritual and Satan's conflict with God-often arise during a period of intense social stresses and cultural crisis. Similarly, the high amounts of violent terms and actions in the Grimm's fairy tales have been shown to be tied up with power and social status in the construction of the self (Alcantud-Diaz, 2010, 2014). In a different study, Haar (2005) analyzes a number of motifs in Chinese witch-hunt stories, such as the consumption of adult human body parts, children, and fetuses, to illustrate the force of the anti-Christian movements and the interplay of folkloric fears and political history in China. This finding is supported by Tian (2014) when looking at the Tianjin Missionary Case of 1870.

In contrast to the wealth of studies on violence in folklore, there is scant research on the act of lying and its implications. This is surprising given how prevalent lying is across folk cultures. Lying tales make up one category of its own within the folktales of Thailand (MacDonald and Vathanaprida, 1994). Research studies that touch on this topic are understandably centered around the themes of honesty/dishonesty and moral development in storytelling (Kim et al., 2018; MacDonald, 2013). In a rare approach that examines the semantics of lies, one study compares the function of lies in folktales to a prosthesis in the domain of discourse, such that the use of lie transforms the story system from horizontal to vertical, hence, action plan to metaaction (Towhidloo and Shairi, 2017).

This survey highlights a gap in the literature on the interactions of different religions or religious teachings with deviant behaviors such as lying and killing in folklore. Even beyond the folkloristic realm, findings also remain inconclusive on the relationships between lying/cheating and religion (Bruggeman and Hart, 1996; Rettinger and Jordan, 2005; Mensah and Azila-Gbettor, 2018), as well as between violence and religion (Purzycki and Gibson, 2011; Atran, 2016; Henrich et al., 2019; Blogowska et al., 2013). The primary reason is perhaps, different cultures or social groups recognize and penalize different sets of moral values (McKay and Whitehouse, 2015; Haidt and Graham, 2007; Haidt and Joseph, 2004; Henrich et al., 2010; Graham et al., 2016). In other words, while all religions stress the need to cultivate virtues such as loyalty, reciprocity, honesty, and moderation, how these virtues are practiced in reality are not universal across cultures. What is equally noteworthy is how certain vices, e.g., lying and violence, are portrayed and tolerated in different parts of the world. An analysis of the cultural history of South Asian has revealed the development of arguments that seemingly rationalize violence, turning violence into non-violence over the course of millennia (Houben and van Kooij, 1999). One example the authors point out is the glorification of the gods and goddesses who have committed the most extreme forms of violence.

Thus, while extant research has not confirmed the relationship between religious teachings and lying and/or violence, the interplay of these two variables may be different and better understood when looking through folklore-a colorful window into folk psychology. This is where the current study fits inthrough the case of Vietnam, it looks at the two universal acts of violence and lies in storytelling to shed light on the influence of traditional religions on folkloristic behaviors.

The three teachings in Vietnam. Before delving in further, it is important to note that the Vietnamese word tôn giáo is not equivalent to its English translation religion, which is derived from the Latin root religio meaning 'to bind together' or 'to reconnect' (Durkheim, 1897). The Vietnamese word has its origin from the Chinese word zongjiao (宗教), which was imported from Japan (shukyo 宗教) in the first decade of the twentieth century (Casadio, 2016, p. 45). The word, comprised of zong as in "divisional lineage" and jiao as in "teaching," encompasses the praxis and doctrine of religion (Casadio, 2016). The word religion in Vietnamese can be interpreted as a "way of life" (the Chinese dao 道) or “teaching” (教) (Tran, 2017). In practice, the Vietnamese popular religion involves ancestor and deity worshiping, exorcism, spirit-possession, etc. (Cleary, 1991; Toan-Anh, 2005; Kendall, 2011; Tran, 2017). For this reason, the present study uses "the Three Teachings" to avoid the religious connotations and to instead refer to their influence in both lifestyle and traditional philosophies.

The fundamental contents of the Three Teachings are presented in Table 1. The details of these religions can be found in Vuong et al. (2018).

As summarized above, the Three Teachings share cultivation of moral character but differ in the process and its end goal. For Confucianism, the process centers around building harmonious relationships with other society members and sustaining the societal structures. For Taoism, the emphasis is instead on protecting one's relationship with nature, keeping the natural flow of life to the point that one may detach oneself entirely from society. For Buddhism, the key to enlightenment (nirvana) is to understand the nature of reality - that life is suffering because one is ignorant of the impermanent nature of things. None of the Three Teachings explicitly forbid lying, though Buddhist teachings do hold "Do not kill” as its first precept.

\section{Materials and method}

Folktales encoding scheme. This paper analyzes the outcome associated with behaviors of lying and violence of the main characters in selected Vietnamese folktales, as well as the association of the Three Teachings with said behaviors. First, we encode the details of 307 Vietnamese folk stories into 345 binary data points, which are coded as blue in Fig. 1.

- Lie: whether the main character lies.

- Viol: whether the main character employs violence

- VB: whether the main characters' behaviors express the value of Buddhism 
Table 1 A summary of key contents of Confucianism, Taoism, and Buddhism as known in Vietnam.

\section{Confucianism}

Earliest presence

in Vietnam

Peak development

Core teachings
From 111 B.C. until A.D. 938 under Chinese

domination (Nguyen, 1998)

Neo-Confucianism grew from the 15th century to its peak in the 19th century during the Nguyen dynasty (Nguyen, 1998, p. 93)

Three moral bonds, three obediences, five cardinal virtues, four virtues (one set for women and another set for general)

moral conduct (đức德), benevolence (nhân 仁), loyalty (trung 忠), wisdom (trí 智), filia piety (hiếu 孝), chastity or purity (tiết 節), righteousness (nghĩa 義), propriety (lễ 禮), integrity/faithfulness (tín 信)

\section{Taoism}

2nd century AD from China (Xu, 2002)

From the 11th to 15th centuries, during the Ly and Tran dynasties (1010-1400) (Xu, 2002)

Letting the natural flow of life, searching for longevity and immortality, and spiritual healing, which gets mixed into Vietnamese popular religious beliefs (Tran, 2017, p. 13)

"effortless action" (vô vi or wuwei 无为),

"spontaneity" (tự nhiên 自然)

\section{Buddhism}

1st or 2nd century AD from India

(Nguyen, 1985; Nguyen, 1993; Nguyen, 1998; Nguyen, 2008;

Nguyen, 2014)

11th century during the Ly dynasty

(Nguyen, 2008, p. 19)

The Four Noble Truths and the Eight-fold Path

Karma (nghiệp): means the spiritual principle of cause and effect. It determines the cycle of reincarnation.

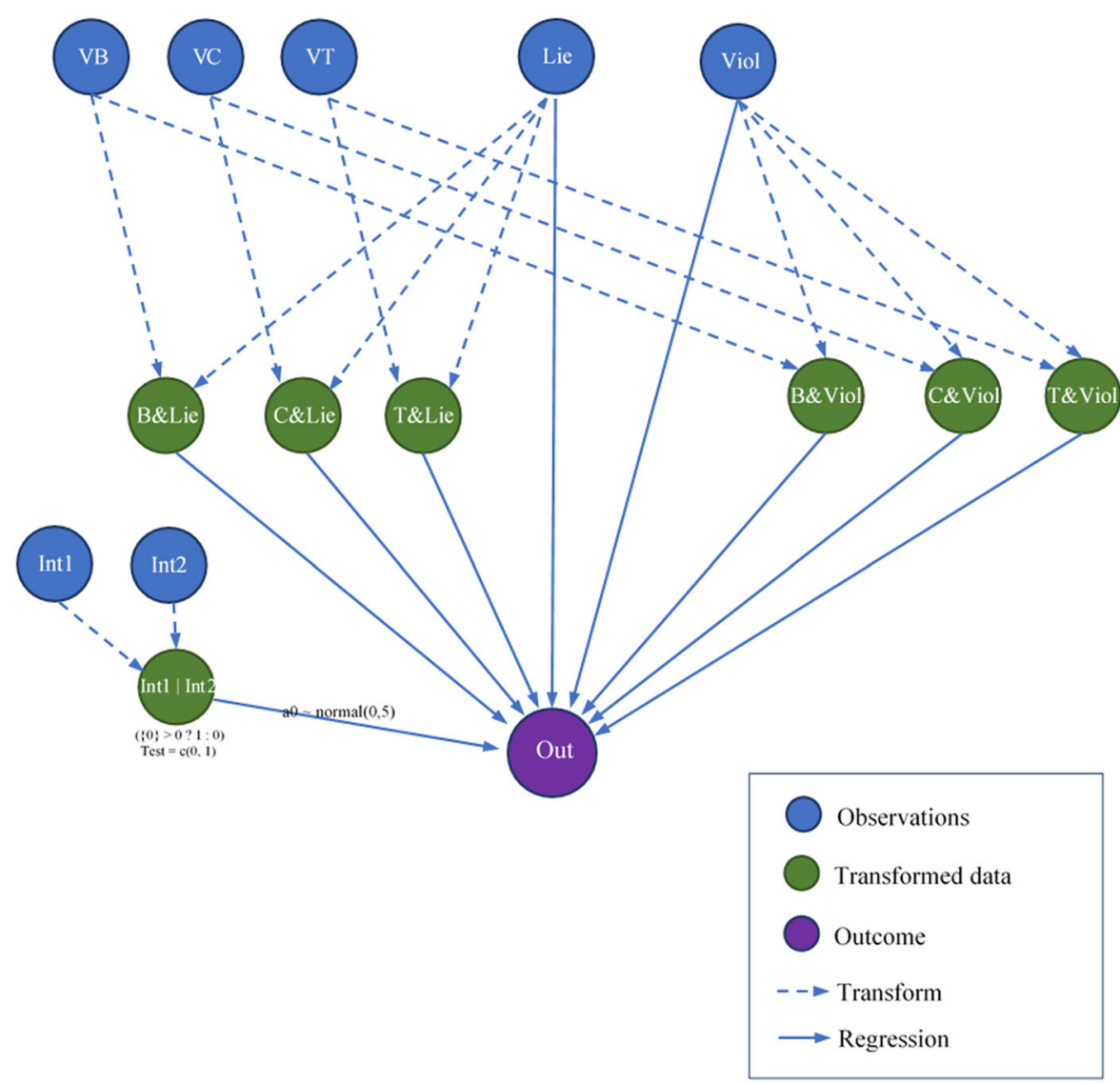

Fig. 1 The Primary Model. The primary model of evaluating the influence of the Three Teachings ("VB", "VC", "VT") on lying ("Lie") and violent behavior ("Viol") of main characters based on the outcome of the folktales.

- VC: whether the main characters' behaviors express the value of Confucianism

- VT: whether the main characters' behaviors express the value of Taoism

- Int1: whether there are interventions from the supernatural world (the Bodhisattva, the Buddha, deities, gods, fairies, etc.)

- Int2: whether there are interventions from human (king, mandarin, good people, etc.)
- Out: whether the outcome of a story is positive for its main characters

All the variables are all binomially distributed, and they are presented by blue nodes in Fig. $1 \bigcirc$. For further details of the coding system, see Vuong et al. (2018). For example, for simplicity's sake, if the main character in a story believes in the law of karma of Buddhism, and lies, and still succeeds in the end, 
then the coding will be "VB" equals 1 , "Lie" equals 1 , and "Out" equals 1 . The details of the stories concerning Confucianism and Taoism are encoded similarly (Vuong et al., 2018; La and Vuong, 2019). We are also interested in whether external intervention from either human ("Int1") or the supernatural ("Int2") might influence the story's outcome. After encoding 307 folktales, to find out credible statistical patterns for the outcome of the main character lied or committed violent acts and at the same time, and their behaviors align with certain core values of the Three Teachings (RQ), the following a multi-level varying intercept model is constructed.

We then perform the Bayesian Markov Chain Monte Carlo (MCMC) analysis based on the multilevel model in Fig. 1. Concretely, we set out to measure the probability of an outcome of a character, given any intervention thereof, and the religious values ("VB", "VC", "VT") and the actions ("Lie," and "Viol"), to which he or she is committed (RQ). The measurement was conducted by applying the Bayesian MCMC estimation of 5000 iterations, 2000 warm-ups, and four chains on the model. Then to check for goodness-of-fit, we will use the Pareto smoothed importance-sampling leave-one-out cross-validation (PSIS-LOO) approach (Vehtari et al., 2017).

There are several advantages of Bayesian multilevel modeling. First, the method helps formalize the use of background knowledge to make more realistic inferences about a particular problem. With multilevel or hierarchical modeling, this idea is taken to another level, where simultaneous analyses of individual quantities are performed (Spiegelhalter, 2019). Second, it reflects the approach of "mathematics on top of common sense" (Scales and Snieder, 1997) with Bayes' theorem makes no assumption about an infinite amount of posterior data, all observations are probabilistic depending on prior distributions and can be updated by conditioning on newly-observed data (Gill, 2002; Kruschke, 2015; McElreath, 2016). The approach is, thus, especially helpful to social sciences where there are various conflicting research philosophies (Vuong et al., 2019). Third, past studies in psychological and ecological sciences have demonstrated this effectiveness and flexibility of multilevel modeling. For example, Doré and Bolger found the data on the impacts of stressful life events on well-being are best fit with a varying curve model rather than a varying slope or a varying intercept model, which shows a wide range of different trajectories in life satisfaction different people to show a wide surrounding a negative life event (Doré and Bolger, 2018). A seminal study by Vallerand shows a hierarchical model of extrinsic and intrinsic motivation not only generates a framework to organize the literature on the subject, but also new and testable hypotheses (Holman and Walker, 2018; Vallerand, 1997).

Model construction. This section deals with the details of the model construction process. First of all, Fig. 1 is a logic map of the causal relationship between different (level) of variables and the outcome ("Out"), and this is a multi-level varying intercept model. To evaluate the influence of the Three Teachings ("VB", "VC", "VT") and negative behaviors ("Lie", and "Viol") on the outcome of the stories, we join the Three Teachings variables with the negative behaviors variables to create transformed data. To evaluate whether the outcome of a story is changed because of an intervention, whether from the supernatural ("Int1") or human ("Int2"), we combine the two observation variables into one new transformed variable. In Fig. 1, the transformed data are represented as green nodes $\bigcirc$, and the relation for transform data is represented in Fig. 1 using the dash-line arrow $(--\triangleright)$ ). Table 2 presents the descriptions and the mathematical formulas of the transformed data.
Mathematical formulae. Taken all the components together, we have the following general formula to evaluate the interplay of violence, lies, and religious teachings in Vietnamese folktales (Eq. 1):

$$
\begin{aligned}
& O \sim b \_B \_a n d \_V i o l \_O^{*} V B^{*} V i o l \\
& +b_{-} C_{-} \text {and_Viol_O* VC*Viol } \\
& +b_{-} T \text { _and_Viol_O* VT*Viol } \\
& +b \_V i o l \_O^{*} V i o l+b \_B \_a n d \_L i e \_O^{*} V B^{*} L i e \\
& +b_{-} C_{-} \text {and LLie_O* } V C^{*} L i e+b_{-} T_{-} \text {and LLie_O* } V T^{*} L i e \\
& +b \_L i e \_O^{*} L i e+a \_I n t 1 \_o r \_I n t 2[(\operatorname{Int} 1+\operatorname{Int} 2>0 ? 1: 0)]
\end{aligned}
$$

As overfitting is a common issue among models with more parameters (McElreath, 2016), we will compare the performance of the Primary Model in Fig. 1 with the following less complex models: (i) a basic model consists of "O", "Viol", and "Lie", whose formula is presented in Eq. 2; (ii) a model which investigates the interplay of violence and religious teachings only-Violence Model in short (Eq. 3); (iii) a model which investigates the interplay of lie and religious teachings only-Lie Model in short (Eq. 4). To execute the model comparison, we deploy the Pareto smoothed importance-sampling leave-one-out cross-validation (PSIS-LOO) approach (Vehtari et al., 2017), and compare the weights of the models by computing the WAIC weights, PseudoBMA weights without Bayesian bootstrap, Pseudo-BMA+ weights with Bayesian bootstrap, and 4) Bayesian stacking weights (Yao et al., 2018; Vehtari and Gabry, 2019).

$$
O \sim b_{-} \text {Viol_O* Viol }+b_{\_} L i e_{-} O^{*} \text { Lie }+a_{-} O
$$

$$
\begin{aligned}
& O \sim b \_B \_a n d \_V i o l \_O^{*} V B^{*} V i o l+b \_C \_a n d \_V i o l \_O^{*} V C^{*} V i o l \\
& +b_{-} T \text { _and_Viol_O* VT*Viol + b_Viol_O*Viol } \\
& +a \_I n t 1 \_o r \_I n t 2[(\operatorname{Int} 1+\operatorname{Int} 2>0 ? 1: 0)]
\end{aligned}
$$

$$
\begin{aligned}
& O \sim b \_B \_a n d \_L i e_{-} O * V B^{*} L i e+b \_C \_a n d L L i e_{-} O^{*} V C^{*} L i e \\
& +b_{-} T \text { _and_Lie_O* } V T^{*} L i e+b_{-} L i e_{-} O^{*} \text { Lie } \\
& \left.\left.+a \_I n t 1 \_ \text {or_Int2 [(Int } 1+\operatorname{Int} 2>0 ? 1: 0\right)\right]
\end{aligned}
$$

The visualizations of the models can also be seen in Supplementary file (Figs. S1-S2).

\section{Analysis results}

\section{Technical validation}

Convergence diagnostics. After running MCMC analyses on all four models, the basic two standard diagnostics demonstrate a good convergence: all Rhat's values are one, and all values of n_eff (effective sample size) are above 1,000 . The detailed summaries of the models are presented in the Appendix. Visualizations of the convergence of the Markov chains, the autocorrelation coefficient, and the Gelman Shrink Factor can be viewed in the Supplementary file (Figs. S3-S10).

Model comparison. Next, using the PSIS-LOO approach, we present the results of the model comparison process in Table 3:

As can be seen in Table 3, the Basic Model performs the best, which is expected due to the straightforward nature of the model. The model fits the data well with all Pareto $k$ estimates being good $(k<0.5)$. When it comes to the more complex models, the PSISLOO results for the Lie Model and Violence Model are compatible, both with $99.7 \%$ of good Pareto $k$ estimates. 
Table 2 Descriptions and mathematical formula of the transformed data.

\begin{tabular}{|c|c|c|}
\hline Transformed data & Description & Mathematical formula \\
\hline B_and_Lie & $\begin{array}{l}\text { The main character behaves according to the core values of Buddhism, yet there are } \\
\text { details/contents in the story showing this character lies. }\end{array}$ & B_and_Lie $=B$ * Lie \\
\hline C_and_Lie & $\begin{array}{l}\text { The main character behaves according to the core values of Confucianism, yet there } \\
\text { are details/contents in the story showing this character lies. }\end{array}$ & $C \_a n d \_L i e=C * L i e$ \\
\hline T_and_Lie & $\begin{array}{l}\text { The main character behaves according to the core values of Buddhism, yet there are } \\
\text { details/contents in the story showing this character lies. }\end{array}$ & $T_{\text {_and_Lie }}=T *$ Lie \\
\hline B_and_Viol & $\begin{array}{l}\text { The main character behaves according to the core values of Buddhism yet commits } \\
\text { violent acts. }\end{array}$ & B_and_Viol $=B$ *Viol \\
\hline T_and_Viol & $\begin{array}{l}\text { The main character behaves according to the core values of Taoism yet commits } \\
\text { violent acts. }\end{array}$ & $T \_$and_Viol $=T * V i \circ 1$ \\
\hline Int1_or_Int2 & $\begin{array}{l}\text { There exists an intervention in a story of either the supernatural or the humans in the } \\
\text { stories. This is the only varying intercept variable in the model as it helps evaluate the } \\
\text { outcome of a folktale in two cases: with and without intervention. }\end{array}$ & $\begin{array}{l}\text { Int1_or_Int2 }=(\text { Int1 }+ \text { Int2 }>0 \\
? 1: 0)\end{array}$ \\
\hline
\end{tabular}

Meanwhile, as expected from the complexity of the Primary Model, it performs the worst with $99.1 \%$ of the Pareto $k$ estimates being good $(k<0.5)$, and $0.3 \%$ being ok $(0.5<k \leq 0.7)$. The visualizations of the Pareto $k$ values for all the models are presented in the Supplementary file (Fig. S11-S14). The PSISLOO results clearly indicate that the goodness-of-fit of each model decreases as its complexity increases.

To further verify the probability of each model, we calculate four different types of weight for each model and rank the models accordingly (see Table 4).

It becomes clear from Table 4 that the Primary Model is the least probable, as it ranks fourth in all indicators, similar to the PSIS-LOO results. As the Primary Model includes many more parameters than the other three, it poses the risk of overfitting. The computing of the model's weights demonstrates as much. However, it should be noted that in two indicators, Pseudo-BMA with Bayesian bootstrap and Bayesian stacking, there is still considerable weight for the Primary Model (0.128 and 0.122, respectively).

The Basic Model should be considered the most probable, given that it ranks the best in all categories except for Bayesian stacking. Here, it is notable that in this category, the weight of the Basic Model is almost similar to the weight of the Violence Model ( 0.217 and 0.216 , respectively). The Violence Model consistently ranks third in all categories. Finally, the Lie Model ranks first in the Bayesian stacking and ranks second in all other indicators.

In sum, the Basic Model and the Lie Model should be considered highly probable, as they both have consistently high weights in all categories. The Violence Model is less likely than the previous two; however, it still has considerable weight in three out of four categories. The Primary Model is the least probable, yet, it also has over $12 \%$ weight Pseudo-BMA with Bayesian bootstrap and Bayesian stacking, the two types recommended by Yao et al. (2018). Given such evidence, the Violence and the Primary Model should not be dismissed. Moreover, considering the current paper investigates how the interplay of negative behaviors (violence and lie) with religious teachings could influence the outcome of folktales, the two models are still useful in helping us make sense of such complex social phenomena. Thus, we choose to present and compare the results of all models, providing a caveat of the overfitting risk of the two least probable models.

\section{Interpreting the results}

Assessing the regression coefficients. First, let's take a look at the results of the most credible model-the Basic Model, which is presented in Fig. 2.
It is clear that violent and lying behaviors tend to bring about the negative outcome for the characters of the folktales, with the coefficients are distributed almost exclusively in the negative range. This tendency is also found in all other models, as can be seen in Figs. 3 and 4.

Second, it can be noted there is a clear similarity in the posterior distribution of the coefficients involved lying in the Primary Model and the Lie Model. Figure 3a, b both show that, generally, lying does not bring about good outcomes for the main character. The coefficient $\mathbf{b} \_\mathbf{L i e} \_\mathbf{O}$ in each model is distributed almost entirely in the negative range, similar to results of the Basic Model in Fig. 2.

However, the trend is more complicated when we consider the interaction of lying with religious teachings. It can be seen in Fig. 3 that Confucianism seems to be the most tolerant of lying. The coefficient b_C_and_Lie_O in each model is distributed almost entirely in the positive range. When there is the influence of Confucianism, it seems more likely that the main character enjoys a good outcome, though he or she might lie. For the interaction with Buddhism and Taoism, the Primary Model and the Lie Model both show an ambivalent effect of lying.

Concerning the effect of violent acts on the outcome of stories, the results of both the Primary and Violence Model indicate that violence tends to produce bad endings for the main characters (Fig. 4). Similar to the result in the case of the Basic Model (Fig. 2), the coefficient b_Viol_O in Fig. 4 is mostly negatively distributed.

Again, when considering violence together with the Three Teachings variable, the effect is not straightforward. In both Fig. $4 \mathrm{a}, \mathrm{b}$, the distribution of coefficients b_C_and_Viol_O and b_T_and_Viol_O overlaps both the positive and negative range, suggesting the interplay of Confucian and Taoist values with violence has ambiguous effects on story outcomes. On the contrary, the distribution of $\mathbf{b} \_$B_and_Viol_O falls almost exclusively within the positive range. The result suggests that when Buddhist values are included, the main character can commit a violent act and still be likely to have a good outcome.

In Figs. 3 and 4, when the full range of the values of the coefficients are taken into consideration, there are cases where the interaction of negative behaviors and the all Three Teachings constitute positive endings for the main characters of the folktales. The pair parameters comparison figures from the Primary Model below underlie this pattern clearly (Fig. 5).

Comparing situations with and without intervention. The respective distributions of coefficients a_Int1_or_Int2[1] and a_Int1_or_Int2[2] have the same curve pattern, as can be seen 
Table 3 Model comparison using PSIS-LOO approach.

\begin{tabular}{|c|c|c|c|c|c|}
\hline Model & \multicolumn{5}{|c|}{ Summary } \\
\hline $\begin{array}{l}\text { Primary Model } \\
\text { (Figure 1; Eq.1) }\end{array}$ & $\begin{array}{l}\text { elpd_loo } \\
\text { p_loo } \\
\text { looic } \\
\text {------ } \\
\text { Monte Carlo } \\
\text { Count Pct. } \\
\text { (-Inf, } 0.5] \\
(0.5,0.7] \\
(0.7,1] \\
(1, \text { Inf) }\end{array}$ & 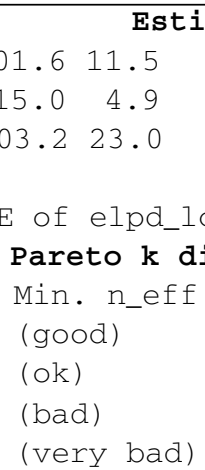 & $\begin{array}{l}\text { IA. } \\
\text { ic val } \\
99.1 \% \\
0.3 \% \\
0.0 \% \\
0.6 \%\end{array}$ & $\begin{array}{l} \\
4844 \\
3729 \\
<\mathrm{NA}> \\
12\end{array}$ & \\
\hline $\begin{array}{l}\text { Basic model } \\
\text { (Eq.2) }\end{array}$ & $\begin{array}{l}\text { elpd_loo } \\
\text { p_loo } \\
\text { looic } \\
\text {------ } \\
\text { Monte Carlo } \\
\text { All Pareto }\end{array}$ & $\begin{array}{ll} & \text { Esti } \\
97.5 & 8.9 \\
3.1 & 0.2 \\
94.9 & 17.8 \\
\text { E of elpd_ld } \\
\text { Pareto k di } \\
\text { estimates a }\end{array}$ & $\begin{array}{l}\text { SE } \\
\\
0 . \\
i c \mathrm{va}] \\
(\mathrm{k}<\end{array}$ & $\begin{array}{l} \\
.51 \\
5\end{array}$ & \\
\hline $\begin{array}{l}\text { Violence model } \\
\text { (Eq.3) }\end{array}$ & $\begin{array}{l}\text { elpd_1oo } \\
\text { p_loo } \\
\text { looic } \\
\text { Monte Carlo } \\
\\
\text { (-Inf, } 0.5] \\
(0.5,0.7] \\
(0.7,1] \\
(1, \text { Inf) }\end{array}$ & $\begin{array}{l}\text { Esti } \\
99.010 .4 \\
8.3 \quad 3.7 \\
97.920 .8 \\
\text { E of elpd_l } \\
\text { Pareto k di } \\
\text { (good) } \\
\text { (ok) } \\
\text { (bad) } \\
\text { (very bad) }\end{array}$ & $\begin{array}{l}\text { SE } \\
\\
\\
\text { TA. } \\
\text { ic val } \\
\text { Pct. } \\
99.7 \% \\
0.0 \% \\
0.0 \% \\
0.3 \%\end{array}$ & $\begin{array}{l}\text { s : } \\
\text { Min. } \\
4061 \\
<\mathrm{NA}> \\
<\mathrm{NA}> \\
14\end{array}$ & n_eff \\
\hline Lie model (Eq.4) & $\begin{array}{l}\text { elpd_1oo } \\
\text { p_loo } \\
\text { looic } \\
\text { Monte Carlo } \\
\text { (-Inf, } 0.5] \\
(0.5,0.7] \\
(0.7,1] \\
(1, \operatorname{Inf})\end{array}$ & $\begin{array}{l}\text { Esti } \\
99.010 .4 \\
8.3 \quad 3.7 \\
97.920 .8 \\
\text { E of elpd_l } \\
\text { Pareto k di } \\
\text { (good) } \\
\text { (ok) } \\
\text { (bad) } \\
\text { (very bad) }\end{array}$ & $\begin{array}{l}\text { SE } \\
\\
\\
\\
\text { JA. } \\
\text { ic val } \\
\text { Pct. } \\
99.7 \% \\
0.0 \% \\
0.0 \% \\
0.3 \%\end{array}$ & $\begin{array}{l} \\
\\
\\
\text { s : } \\
\text { Min. } \\
4061 \\
<\mathrm{NA}> \\
<\mathrm{NA}> \\
14\end{array}$ & n_eff \\
\hline
\end{tabular}

from Fig. 6. This suggests that when there are external interventions, improvements in main character behaviors compared to when there are no interventions are negligible. In other words, the ending of a story does not depend significantly on the nature of external interventions. The detailed results of the Interventional coefficients of all models can be seen in the Appendix.

\section{Discussion}

Limitations and technical implications. The present study is not exempt from limitations. First, given the dataset only covers Vietnamese folktales, one should be cautious about generalizing the results. Data on folktales of different countries, regions, and cultural settings should be collected and analyzed to move beyond the country-specific nature here. Besides, the folktales can be subjected to a different method of coding; for example, the variable "violence" can be further broken down to "murder", "assault", etc. Limitations aside, the use of Bayesian multilevel modeling and the MCMC method of data simulation in this study has enabled us to efficiently analyze the complex relationships among different variables-such as the religious teachings/values and the acts of lying and violence-when the amount of data is limited. Studies on Vietnamese folklore, though insightful in their own rights, have remained qualitative and touched on some 
Table 4 Model weights comparison and model ranking.

\begin{tabular}{|c|c|c|c|c|}
\hline Weights & WAIC & $\begin{array}{l}\text { Pseudo-BMA without } \\
\text { Bayesian bootstrap }\end{array}$ & $\begin{array}{l}\text { Pseudo-BMA with } \\
\text { Bayesian bootstrap }\end{array}$ & Bayesian stacking \\
\hline Primary model (Eq. 1) & 0.063 & 0.016 & 0.128 & 0.122 \\
\hline Violence model (Eq. 3) & 0.118 & 0.068 & 0.181 & 0.216 \\
\hline Lie model (Eq. 4) & 0.287 & 0.173 & 0.307 & 0.445 \\
\hline $\begin{array}{l}\text { Model ranking (from the } \\
\text { best to the worst) }\end{array}$ & $\begin{array}{l}\text { Basic, Lie, } \\
\text { Violence, Primary }\end{array}$ & $\begin{array}{l}\text { Basic, Lie, Violence, } \\
\text { Primary }\end{array}$ & $\begin{array}{l}\text { Basic, Lie, Violence, } \\
\text { Primary }\end{array}$ & $\begin{array}{l}\text { Lie, Basic, } \\
\text { Violence, Primary }\end{array}$ \\
\hline
\end{tabular}
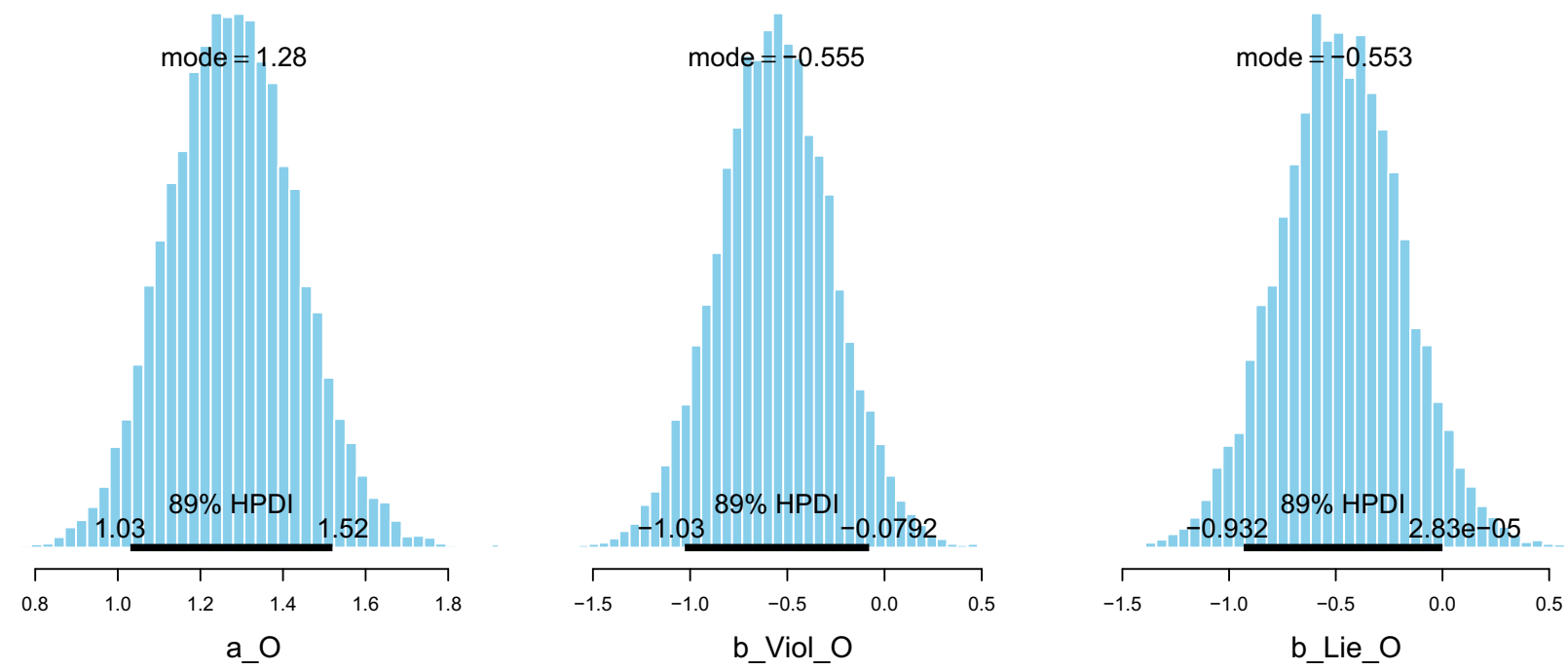

Fig. 2 Distribution of the coefficients of the Basic Model (Eq. 2).

themes such as femininity-masculinity (Nguyen, 2002; Do and Brennan, 2015), folk medical practices (Du, 1980), or psychological mindedness (Nguyễn et al., 1991). Here, the computational method suggests there is a fertile ground for novel and interdisciplinary quantitative research on culture, religion, ethics, sociology, and many other social science disciplines (Peels and Bouter, 2018; Pedersen, 2016).

Implications for the three teachings of Confucianism, Buddhism, and Taoism. This study asks what outcome, statistically, can be expected from the interaction of negative behaviors and the values of the Three Teachings in folktales. And one of the most striking results of this study is how, in stories with Buddhist teachings, the acts of violence are often linked to a positive outcome. This finding brings us back to the opening Buddhist story on the monk who turns into a coucal and the murderous robber who gets salvation. It also resonates with what Houben and van Kooij (1999) have once pointed out, i.e., the prevalence of violence and the rationalization of violence in South Asian folklore, particularly in stories influenced by Buddhism and Hinduism. To make sense of the underlying mechanism behind this statistical pattern, we suggest examining which values in the Three Teachings are most observed by the laypeople. The tolerance for violence can be explained by the emphasis on karma in Buddhism - a concept that might be loosely interpreted as "what goes around, comes around" or "an eye for an eye". Broadly speaking, the law of karma maintains a sort of cosmic justice according to which all crimes are punished and deeds are rewarded, suitably, in the long run (Gombrich, 1975); including from one lifetime to another. While one may argue that the karmic doctrine is much more intricate than just this and varies according to the teachings of different branches of Buddhism, this simplistic view is more likely to be how the principle was perceived by the average person. Another way to interpret the findings is how violence can serve as a stark contrast with the purity and beauty of Buddhist-espoused virtues such as compassion, renunciation, and tranquility.

Another interesting finding how in stories with Confucian teachings, characters who lie tend to enjoy desirable outcomes, statistically speaking. The propensity for lying is attributable to the need to preserve social order and being loyal and pious toward one's King and kins in Confucianism. In historical terms, Confucianism first started as a remedy to the chaotic, violent time of the Spring-Autumn Warring States. As the Chinese teaching prioritizes social order, understandably they would be antithetical to the conspicuous display of violence and more acceptant to lying as the price in practice. That being said, the acceptance of such behavior could still present philosophical and practical dilemma, especially in the case of Confucianism which boasts sets of concrete moral rules. An example of how the Confucian doctrine rationalized passive actions such as lying by omission is a story in which the loyalty of the son to his father and the duty of a man to his ruler are pitted against each other if the father transgresses the law (Bi and D'Agostino, 2004). From a practical point of view, the prevalence of Confucian principles in a culture could factor into social interactions, such as when the standard practice of obtaining informed patient consent by medical professionals was complicated by Confucian ethics (Fan, 2000). 

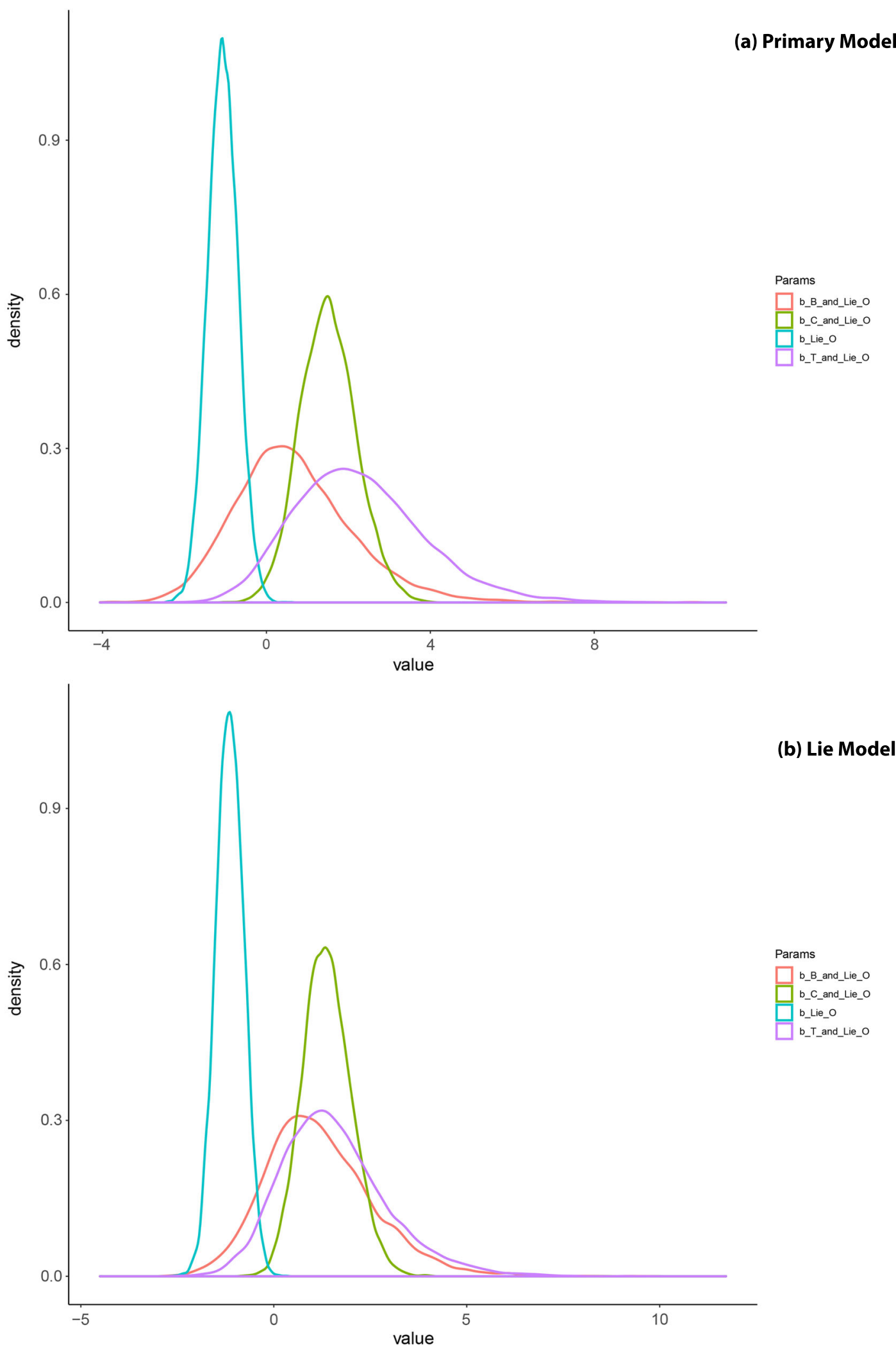

(b) Lie Model

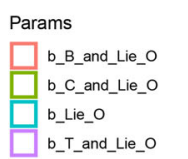

Fig. 3 Comparison of the Primary Model and the Lie Model. (a) Distribution of coefficients of variables involving lying in the Primary Model (Eq. 1); (b) Distribution of coefficients of variables involving lying in the Lie Model (Eq. 4).

Implications for folkloristic and behavioral studies. The findings add to the literature on discrepancies between folklore and real-life conduct that can be found throughout the world, in the stories of Grimm brothers, the folktales of the Native American Zuni, or even as far back as the Greek mythologies-in which the gods were known to commit many crimes that mortals would be punished for. Lies and violence are only two among many actions found in folktales but are both considered as prohibited or shocking in real life. In an analysis on the functions of folklore, Bascom (1954) notes unacceptable 

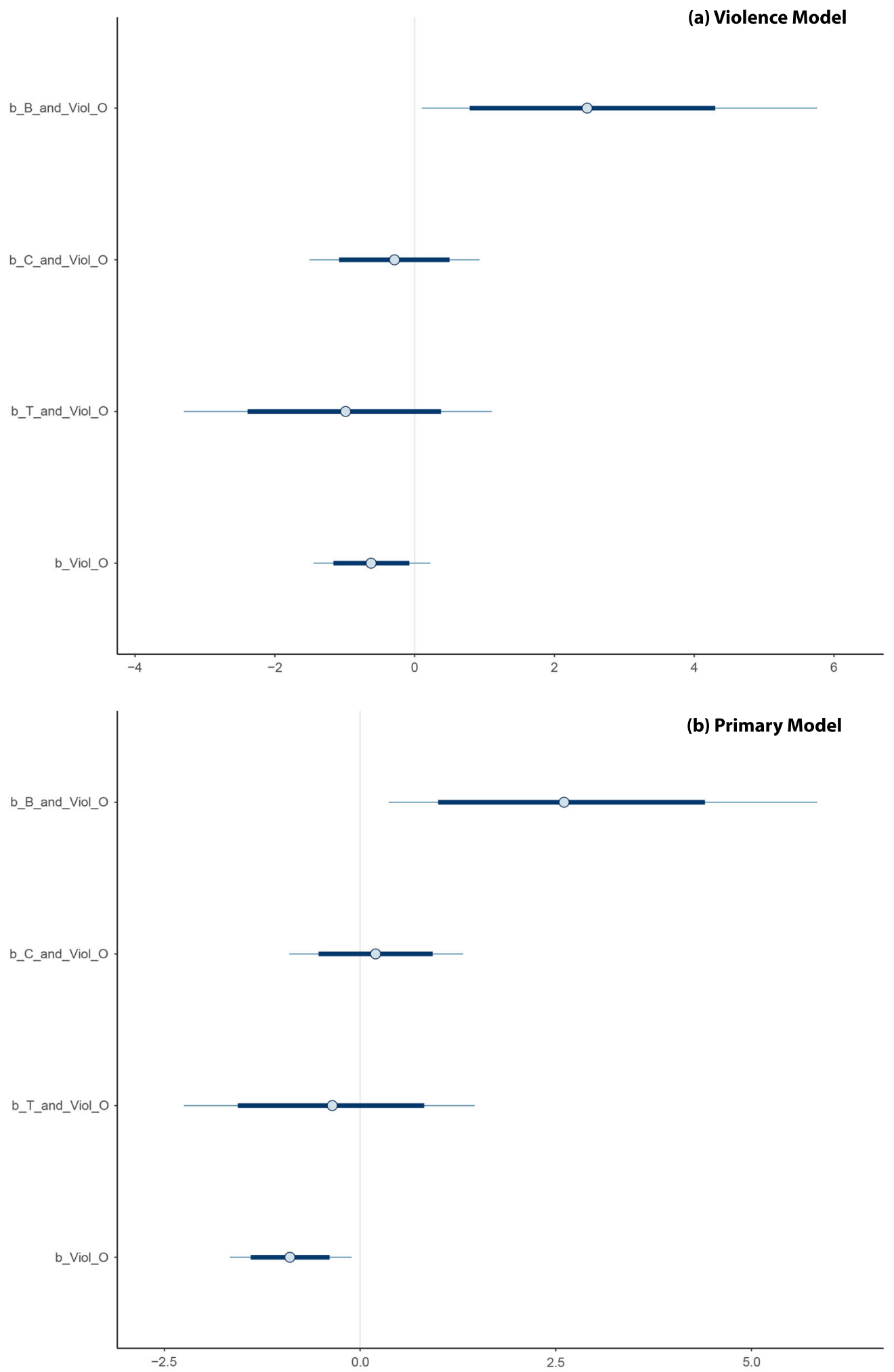

Fig. 4 Comparison of the Primary Model and the Violence Model. Distribution of coefficients of variables involving violent acts in (a) the Primary Model (Eq. 1) and (b) the Violence Model (Eq. 3).

explanations to the tales of violence or polygamy among the Native American peoples of Zuni and the sociologicalpsychological implications that entail. Here, it is important to remember that, while folklore may reflect the values and norms of people and their cultures, many of the extraordinary elements in folklore do not necessarily represent real practices due to the role of day-dreams or wish-fulfillment in traditional oral narratives (Bascom, 1954).

Similarly, in the context of this study's findings, given that all the stories were passed down through the oral tradition, they presumably do not evoke the true ideals of three Teachings, but instead reflect the psychology and understanding of the people at the 

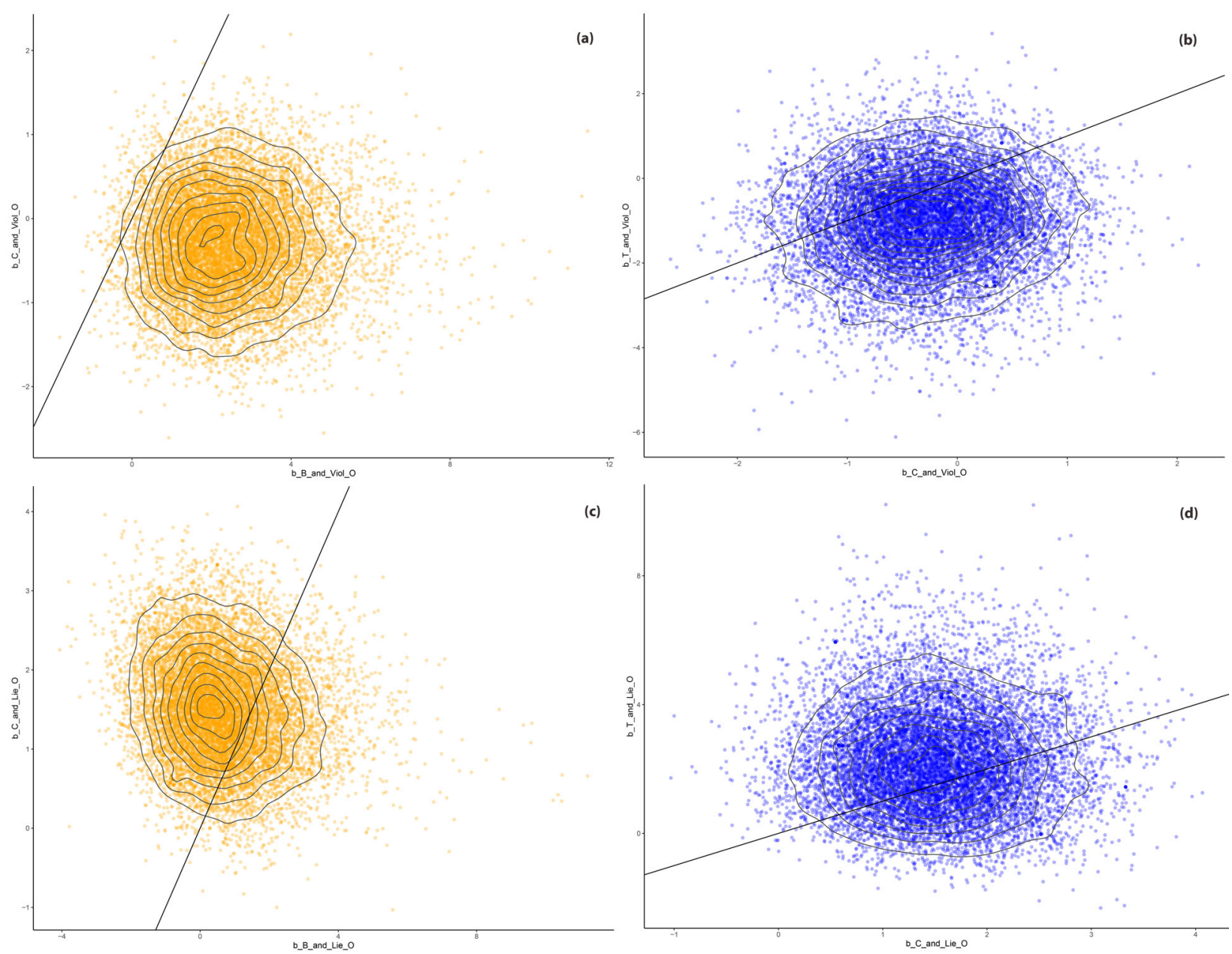

Fig. 5 Pair parameters comparison. (a) b_B_and_Viol_O and b_C_and_Viol_O; (b) b_T_and_Viol_O and b_C_and_Viol_O; (c) b_B_and_Lie_O and b_C_and_Lie_O (d) b_T_and_Lie_O and b_C_and_Lie_O of the Primary Model.

time. What is highlighted here is a glaring double standard in the interpretation and practice of the teachings: the very virtuous outcomes being preached, whether that be compassion and meditation in Buddhism, societal order in Confucianism, appear to accommodate two universal vices-violence in Buddhism and lying in the Confucianism. Attempts to make sense of contradictory human behaviors have pointed out the role of cognition in belief maintenance and motivated reasoning in discounting counterargument (Kaplan et al., 2016; Bersoff, 1999). When it comes to religion, an individual's tolerance of contradictory religious teachings is not due to lower rationality standards but rather due to how such teachings fit the "inference machinery" in a plausible manner (Boyer, 2001). This study takes a step further by showing how "happy endings" can still be accepted as a plausible outcome for deviant behaviors such as lying or committing violence. Generations have passed down these folktales, orally and then in written forms, without ever questioning the incongruence between the upholding of Buddhist, Taoist or Confucian values on one hand, and the absence of punishment on the other. Even if the findings were limited to empirical evidence exclusively within the folkloristic realm, one ought not shy from the troubling implication: the promotion of the ends-justify-the-means mentality when the acceptance of values counter to one's beliefs is correlated with positive outcomes.

\section{Conclusion}

The present study, through the Bayesian network analysis of 307 Vietnamese folktales, has reached two notable conclusions. First, folktale characters who commit either lying or violence face negative outcomes in general (Figs. 2-4), but there is a mixed result when the religious values are taken into consideration. In particular, lying for characters associated with Confucianism tends to bring about a positive outcome (Fig. 3). Second, the character whose behaviors are associated with Buddhism tends to have a happy ending even when he/she commits violence (Fig. 4). When we consider the full range of all the coefficients, the statistical pattern indicates there can be cases where the interaction of the deviant acts with all Three Teachings would all lead to positive consequences (Fig. 5).

These findings, first and foremost, speak to the psychology and understanding of the storytellers of the time. As Bascom has succinctly put:

"Here, indeed, is the basic paradox of folklore, that while it plays a vital role in transmitting and maintaining the institutions of culture and in forcing the individual to conform to them, at the same time it provides socially approved outlets for the repressions which these same institutions impose upon him." (Bascom,1954, p. 349)

Moreover, they could also raise questions about the double standard when people interpret and practice the teachings of Buddhism, Confucianism, and Taoism. Although the three Teachings preach that one ought to cultivate moral characters, it seems in folktales, as well as in life, followers of such teachings are no exception to the two universal vices: lying and violence. 


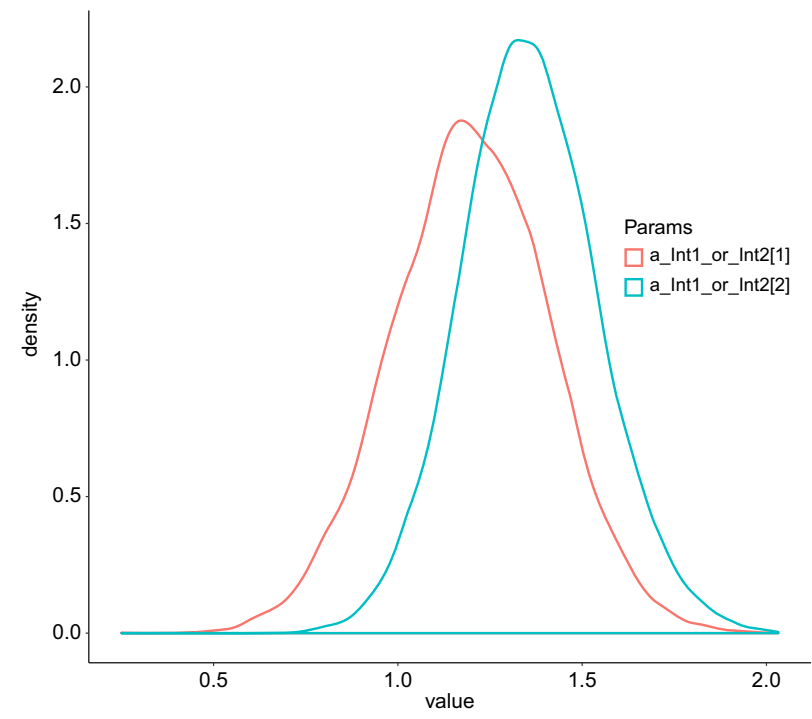

Fig. 6 Distribution of a_Int1_or_Int2[1] and a_Int1_or_Int2[2] from the Primary Model.

Moreover, in certain cases, these vices may bring about by positive outcomes, as detected by the statistical technique deployed in this study. Such contradiction calls into questions the complexity of human decision-making, especially beyond the folklore realm.

\section{Data availability}

The dataset is available from the Github (https://github.com/ sshpa/bayesvl/tree/master/data), and CRAN 'bayesvl' R package (https://cran.r-project.org/package=bayesvl). The executable computer code for this paper is provided in the available on https://github.com/sshpa/bayesvl/tree/master/examples, file: simulation_example.R.

Received: 30 August 2019; Accepted: 23 March 2020;

Published online: 04 May 2020

\section{References}

Abello J, Broadwell P, Tangherlini TR (2012) Computational folkloristics. Commun ACM 55(7):60-70

Albrecht SL, Chadwick BA, Alcorn DS (1977) Religiosity and deviance: application of an attitude-behavior contingent consistency model. J Sci Study Relig 16 (3):263-274

Alcantud-Diaz M (2010) Violence in the Brothers Grimmas fairy tales: a corpusbased approach. Revista Alicantina de Estudios Ingleses 23(2010):173-185

Alcantud-Diaz M (2014) "Kill her, and bring me back her heart as a Token!" identity, power and violence in the Grimm's fairy tales collection. Int J Stud Engl Lang Lit 2:84-99

Atran S (2016) The devoted actor: unconditional commitment and intractable conflict across cultures. Curr Anthropol 57(S13):S192-S203

Bascom WR (1954) Four functions of folklore. J Am Folk 67(266):333-349

Benda BB (2002) Religion and violent offenders in boot camp: a structural equation model. J Res Crime Delinquency 39(1):91-121

Bersoff DM (1999) Why good people sometimes do bad things: motivated reasoning and unethical behavior. Personal Soc Psychol Bull 25(1):28-39

Bi L, D’Agostino F (2004) The doctrine of filial piety: a philosophical analysis of the concealment case. J Chin Philos 31(4):451-467

Blogowska J, Lambert C, Saroglou V (2013) Religious prosociality and aggression: it's real. J Sci Study Relig 52(3):524-536

Bortolini E, Pagani L, Crema ER, Sarno S, Barbieri C, Boattini A, Sazzini M, Da Silva SG, Martini G, Metspalu M (2017a) Inferring patterns of folktale diffusion using genomic data. Proc Natl Acad Sci USA 114(34):9140-9145

Bortolini E, Pagani L, Crema ER, Sarno S, Barbieri C, Boattini A, Sazzini M, da Silva SG, Martini G, Metspalu M (2017b) Reply to d'Huy et al.: navigating biases and charting new ground in the cultural diffusion of folktales. Proc Natl Acad Sci USA 114(41):E8556-E8556

Boyer P (2001) Religion explained: the evolutionary orgins of religious thought. Basic Books, New York

Bruggeman EL, Hart KJ (1996) Cheating, lying, and moral reasoning by religious and secular high school students. J Educ Res 89(6):340-344

Casadio G (2016) Historicizing and translating religion. The Oxford Handbook of the Study of Religion. Oxford University Press, Oxford

Chima A, Helen G (2015) Evil and superstition in Sub-Saharan Africa: religious infanticide and filicide perceiving evil. In: Farnell D, Noiva R, Smith K (eds) Perceiving evil: evil women and the feminine. Brill, Leiden, pp. 33-48

Cleary JC (1991) Buddhism and popular religion in medieval Vietnam. J Am Acad Relig 59(1):93-118

Cochran JK, Akers RL (1989) Beyond hellfire: an exploration of the variable effects of religiosity on adolescent marijuana and alcohol use. J Res Crime Delinquency 26(3):198-225

Corcoran KE, Pettinicchio D, Robbins B (2012) Religion and the acceptability of white-collar crime: a cross-national analysis. J Sci Study Relig 51(3):542-567

Coupland J, Jaworski A (2003) Transgression and intimacy in recreational talk narratives. Res Lang Soc Interact 36(1):85-106

Day A, Vincett G, Cotter CR (eds) (2016) Social identities between the sacred and the secular (Ashgate AHRC/ESRC Religion and Society). Aldershot, Ashgate

d'Huy J, Le Quellec J-L, Berezkin Y, Lajoye P, Uther H-J (2017) Studying folktale diffusion needs unbiased dataset. Proc Natl Acad Sci USA 114:201714884

Do VHT, Brennan M (2015) Complexities of Vietnamese femininities: a resource for rethinking women's university leadership practices. Gend Educ 27 (3):273-287

Dogra S (2018) Folklore and computers: the oral and the digital in computational folkloristics. Int J Human Soc Sci 6(1):22-27

Doré B, Bolger N (2018) Population-and individual-level changes in life satisfaction surrounding major life stressors. Soc Psychol Personal Sci 9(7):875-884

Du JN (1980) Pseudobattered child syndrome in Vietnamese immigrant children. Can Med Assoc J 122(4):394

Durkheim E (1897) Le suicide. Presses Électroniques de France, Paris

Evans TD, Cullen FT, Dunaway RG, Burton Jr VS (1995) Religion and crime reexamined: the impact of religion, secular controls, and social ecology on adult criminality. Criminology 33(2):195-224

Fan R (2000) Informed consent and truth telling: the Chinese confucian moral perspective. HEC Forum 12(1):87-95

Festinger L (1962) A theory of cognitive dissonance. Stanford University Press

Gill J (2002) Bayesian methods: a social and behavioral sciences approach. Chapman and Hall/CRC

Gombrich R (1975) Buddhist karma and social control. Comp Stud Soc Hist 17 (2):212-220

Graham J, Meindl P, Beall E, Johnson KM, Zhang L (2016) Cultural differences in moral judgment and behavior, across and within societies. Curr Opin Psychol 8:125-130

Haar BT (2005) Telling Stories. Brill, Leiden

Haidt J, Graham J (2007) When morality opposes justice: conservatives have moral intuitions that liberals may not recognize. Soc Justice Res 20(1):98-116

Haidt J, Joseph C (2004) Intuitive ethics: how innately prepared intuitions generate culturally variable virtues. Daedalus 133(4):55-66

Henrich J, Bauer M, Cassar A, Chytilová J, Purzycki BG (2019) War increases religiosity. Nat Hum Behav 3(2):129-135

Henrich J, Heine SJ, Norenzayan A (2010) The weirdest people in the world? Behav Brain Sci 33(2-3):61-83

Hirschi T, Stark R (1969) Hellfire and delinquency. Soc Probl 17(2):202-213

Holman D, Walker A (2018) Social Quality and Health: examining individual and neighbourhood contextual effects using a multilevel modelling approach. Soc Indic Res 138(1):245-270

Houben JEM, van Kooij KR (eds) (1999) Violence denied: violence, non-violence and the rationalization of violence in South Asian cultural history. Brill

Kaplan JT, Gimbel SI, Harris S (2016) Neural correlates of maintaining one's political beliefs in the face of counterevidence. Sci Rep. 6:39589

Kendall L (2011) Gods, gifts, markets, and superstition: spirited consumption from Korea to Vietnam. In: Endres KW, Lauser A (eds) Engaging the Sprit World: Popular Beliefs and Practices in Modern Southeast Asia. Berghan Books, Oxford, New York. pp. 103-120

Kim SJ, Song A, Lee G-L, Bach A (2018) Using animated folktales to teach cultural values: a case study with Korean-American bilingual kindergartners. J Res Child Educ 32(3):295-309

Kruschke JK (2015) Doing Bayesian data analysis: a tutorial with R, JAGS, and Stan, 2nd edn. Elsevier, London

La VP, Vuong QH (2019) bayesvl: Visually learning the graphical structure of Bayesian networks and performing MCMC with 'Stan'. The Comprehensive R Archive Network. https://cran.r-project.org/package=bayesvl;version 0.8 .5 (officially published on 24 May 2019) 
MacDonald MR (2013) Sharing SE Asian Folktales for Character Education. IBBY Asia Oceania Conference Bali. http://www.ibby.org/fileadmin/user_upload/04Margaret_MacDonald-Sharing_SE_Asian_Folktales_for_Character_Education. pdf (Accessed 16 Sep 2019)

MacDonald MR, Vathanaprida S (1994) Thai tales: folktales of Thailand (World Folklore Series). Libraries Unlimited, Exeter

McElreath R (2016) Statistical rethinking: a Bayesian course with examples in R and Stan. CRC Press, Boca Raton

McKay R, Whitehouse H (2015) Religion and morality. Psychol Bull 141 (2):447-473

Meehan B (1994) Son of Cain or Son of Sam? The monster as serial killer in Beowulf. Conn Rev 16(2):1-7

Mensah C, Azila-Gbettor EM (2018) Religiosity and students' examination cheating: evidence from Ghana. Int J Educ Manag 32(6):1156-1172

Michalopoulos S, Xue MM (2019) Folklore. National Bureau of Economic Research Working Paper Series No. 25430

Møller AP, Morelli F, Tryjanowski P (2017) Cuckoo folklore and human wellbeing: Cuckoo calls predict how long farmers live. Ecol Indic 72:766-768

Nguyen MD (1985) Culture shock-A review of Vietnamese culture and its concepts of health and disease. Cross-cult Med 142(3):409-412

Nguyen TA (1993) Buddhism and Vietnamese society throughout history. South East Asia Res 1(1):98-114

Nguyen NH (1998) The Confucian incursion into Vietnam. In: Slote WH, Vos GAD (eds) Confucianism and the family: a study of Indo-Tibetan scholasticism. SUNY Press. pp. 91-104

Nguyen VK (2002) Rethinking the status of Vietnamese women in folklore and oral history. In: Brocheux P, Bousquet GL (eds) Viet-Nam Expose-French Scholarship on Twentieth-Century Vietnamese Society. University of Michigan Press, Ann Arbor

Nguyen TT (2008) History of Buddhism in Vietnam. Cultural Heritage and Contemporary Change. Series Iii, Asia (Book 5). Council for Research in Values and Philosophy, Washington, D.C

Nguyen L (2014) Viet Nam Phat Giao Su Luan [On the history of Buddhism in Vietnam]. NXB Van hoc, Hanoi, Vietnam

Nguyễn N, Foulks EF, Carlin K (1991) Proverbs as psychological interpretations among Vietnamese. Asian Folk Stud 50(2):311-318

Nguyen D, Trieschnigg D, Theune M (2013) 'Folktale classification using learning to rank'. European Conference on Information Retrieval. Springer, pp. 195-206

Nikolić D, Bakarić N (2016) What makes our tongues twist?: computational analysis of Croatian tongue-twisters. J Am Folk 129(511):43-54

Pedersen DB (2016) Integrating social sciences and humanities in interdisciplinary research. Pal Commun 2(1):16036

Peels R, Bouter L (2018) The possibility and desirability of replication in the humanities. Pal Commun 4(1):95

Perrin RD (2000) Religiosity and honesty: continuing the search for the consequential dimension. Rev Religious Res 41(4):534-544

Purzycki BG, Gibson K (2011) Religion and violence: an anthropological study on religious belief and violent behavior. Skeptic 16(2):22-27

Rettinger DA, Jordan AE (2005) The relations among religion, motivation, and college cheating: a natural experiment. Ethics Behav 15(2):107-129

Rohrbaugh J, Jessor R (1975) Religiosity in youth: a personal control against deviant behavior1. J Personal 43(1):136-155

Rohrbaugh J, Jessor R (2017) Religiosity: a personal control against delinquency. In: Jessor R (ed) Problem Behavior Theory and Adolescent Health: The Collected Works of Richard Jessor, Volume 2. Springer International Publishing: Cham, pp. 393-409

Sandberg S (2014) What can "lies" tell us about life? Notes towards a framework of narrative criminology. In: Copes $\mathrm{H}$ (ed) Advancing Qualitative Methods in Criminology and Criminal Justice. Routledge, pp. 68-86

Sandberg S, Tutenges S, Copes H (2015) Stories of violence: a narrative criminological study of ambiguity. Br J Criminol 55(6):1168-1186

Scales JA, Snieder R (1997) To Bayes or not to Bayes? Geopolitics 62(4):1045-1046

Spiegelhalter D (2019) The art of statistics: learning from data. Penguin Random House UK, London

Sumerau JE, Cragun RT (2016) "I think some people need religion": the social construction of nonreligious moral identities. Sociol Relig 77(4):386-407

Tangherlini TR (2013) The folklore macroscope. West Folk 72(1):7-27

Tehrani JJ, d'Huy J (2017) Phylogenetics meets folklore: bioinformatics approaches to the study of international folktales. In: Kenna R, MacCarron M, MacCarron P(eds) Maths Meets Myths: Quantitative Approaches to Ancient Narratives. Understanding Complex Systems. Springer, Cham, p 91-114

Thenmozhi K, Anusuya N, Ajmal Ali M, Jamuna S, Karthika K, Venkatachalapathi A, Al-Hemaid FM, Farah MA, Paulsamy S (2018) Pharmacological credence of the folklore use of Bauhinia malabarica in the management of jaundice. Saudi J Biol Sci 25(1):22-26

Tian X (2014) Rumor and secret space: organ-snatching tales and medical missions in nineteenth-century China. Mod China 41(2):197-236

Tittle CR, Welch MR (1983) Religiosity and deviance: toward a contingency theory of constraining effects. Soc Forces 61(3):653-682

Toan-Anh (2005) Nep cu: Tin nguong in Vietnam (Quyen thuong) [Old habits: Religious beliefs in Vietnam (Vol. I)]. Hanoi: Nha Xuat Ban Tre.

Towhidloo Y, Shairi HR (2017) A study of making prostheses in discourse: why does narrative lie make prostheses? Res Contemp Word Lit 22(1 \#A00119):269-286

Tran AQ (2017) Gods, heroes, and ancestors: an interreligious encounter in eighteenth-century Vietnam. Oxford University Press

Vallerand RJ (1997) Toward a hierarchical model of intrinsic and extrinsic motivation. In: Zanna MP (ed) Advances in experimental social psychology. Vol. 271-360. Academic Press

Vehtari A, Gabry J (2019) Bayesian Stacking and Pseudo-BMA weights using the loo package. loo 2.2.0. https://mc-stan.org/loo/articles/loo2-weights.html (Accessed 17 Mar 2020)

Vehtari A, Gelman A, Gabry J (2017) Practical Bayesian model evaluation using leave-one-out cross-validation and WAIC. Stat Comput 27(5):1413-1432

Victor J (1990) Satanic cult rumors as contemporary legend. West Folk 49(1):51-81

Vuong Q-H, Bui Q-K, La V-P, Vuong T-T, Nguyen V-HT, Ho M-T, Nguyen HKT, Ho M-T (2018) Cultural additivity: behavioural insights from the interaction of Confucianism, Buddhism and Taoism in folktales. Pal Commun 4(1):143

Vuong QH, Ho M-T, La VP (2019) 'Stargazing' and p-hacking behaviours in social sciences: some insights from a developing country. Eur Sci Editing 45 (2):54-55

Wainryb C, Pasupathi M (2015) Saints, and the rest of us: broadening the perspective on moral identity development. Hum Dev 58(3):154-163

Wang X, Jang JS (2018) The effects of provincial and individual religiosity on deviance in China: a multilevel modeling test of the moral community thesis. Religions 9(7):202

Welch MR, Tittle CR, Grasmick HG (2006) Christian religiosity, self-control and social conformity. Soc Forces 84(3):1605-1623

$\mathrm{Xu}$ YZ (2002) A thesis on the spreading and influence of Taoism in Vietnam. J Historical Sci 7:015

Yao Y, Vehtari A, Simpson D, Gelman A (2018) Using stacking to average Bayesian predictive distributions (with discussion). Bayesian Anal 13(3):917-1007

Yun I, Lee J (2016) The relationship between religiosity and deviance among adolescents in a religiously pluralistic society. Int J Offender Ther Comp Criminol 61(15):1739-1759

\section{Competing interests}

The authors declare no competing interests.

\section{Additional information}

Supplementary information is available for this paper at https://doi.org/10.1057/s41599020-0442-3.

Correspondence and requests for materials should be addressed to Q.-H.V. or M.-T.H.

Reprints and permission information is available at http://www.nature.com/reprints

Publisher's note Springer Nature remains neutral with regard to jurisdictional claims in published maps and institutional affiliations.

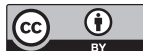

Open Access This article is licensed under a Creative Commons Attribution 4.0 International License, which permits use, sharing adaptation, distribution and reproduction in any medium or format, as long as you give appropriate credit to the original author(s) and the source, provide a link to the Creative Commons license, and indicate if changes were made. The images or other third party material in this article are included in the article's Creative Commons license, unless indicated otherwise in a credit line to the material. If material is not included in the article's Creative Commons license and your intended use is not permitted by statutory regulation or exceeds the permitted use, you will need to obtain permission directly from the copyright holder. To view a copy of this license, visit http://creativecommons.org/ licenses/by/4.0/.

(C) The Author(s) 2020 